\title{
Bed Load Transport of Mixed Size Sediment: Fractional Transport Rates, Bed Forms, and the Development of a Coarse Bed Surface Layer
}

\author{
Peter R. WiLcock \\ Department of Geography and Environmental Engineering, The Johns Hopkins University, Baltimore, Maryland
}

\author{
JOHN B. SOUTHARD
}

Department of Earth, Atmospheric, and Planetary Sciences, Massachusetrs Institute of Technology, Cambridge

\begin{abstract}
Fractional transport rates, bed surface texture, and bed configuration were measured after a mixed size sediment had reached an equilibrium transport state for seven different flow strengths in a recirculating laboratory flume. Fractional transport rates were also measured at the beginning of each run when the bed was well mixed and planar. The start-up observations allow us to describe the variation of fractional transport rates with bed shear stress for a constant bed surface texture and bed configuration. The start-up and equilibrium observations together allow, for the first time, an unambiguous description of the mutual adjustment among the transport, the bed configuration, and the bed surface, as the transport system moves toward equilibrium. We find that a substantial interaction exists among the transport, bed surface, and bed configuration. Bed forms and a coarse surface layer coexist over a range of bed shear stress. Under some flow conditions the size and shape of the bed forms are controlled by the presence of the coarse surface layer. At higher flows the coarse surface layer is eliminated by scour in the lee of the bed forms. If the bed surface is defined as that over which the bed forms move, a coherent relation between the bed surface texture and the transport grain size distribution may be defined. At equilibrium the transport rates of all fractions were not equally mobile, defined as identical transport and bed grain size distributions, although equal mobility was approached for runs in which the bed shear stress was more than twice that for initial motion of the mixture. Under some flow conditions the transport was observed to adjust away from equal mobility as the bed adjusted from a well-mixed start-up condition to an equilibrium state. Development of a partial static armor, wherein some individual grains become essentially immobile even though other grains in the same fraction remain in transport, is suggested to explain these adjustments between the transport and bed surface grain size distributions. Constraints on equilibrium mixed size sediment transport are defined. The special conditions for which equal mobility must hold and the relevance to natural conditions of flume results and the equal mobility concept are discussed.
\end{abstract}

\section{INTRODUCTION}

When sediment of a single size is transported in the presence of bed forms, a strong interaction exists between the sediment transport and the bed configuration. Bed forms are created by the moving sediment, and their size, shape, and speed depend on the sediment transport rate. But the magnitude and direction of sediment transport also varies in space and time with migration of the bed forms. In the absence of a unifying model of sediment transport and bed form genesis and stability, transport and bed configuration are best considered as two classes of mutually interacting, dependent variables: efforts to understand one depend on an understanding of the other. When a sediment bed contains a mixture of grain sizes, an additional class of dependent variable, the grain size distributions of the bed surface and the immediate subsurface, may vary during transport. The transport rates of individual size fractions (as well as the total transport rate) depend on the population of grain sizes available for transport on the bed surface. At the same time the grain size distribution of the bed surface depends on the mobility of the various grain sizes in the bed. Similarly, the texture of the bed surface may influence the growth of bed

Copyright 1989 by the American Geophysical Union.

Paper number 89 WR00740.

0043-1397/89/89WR-00740\$05.00 forms by controlling the depth to which bed form troughs may be scoured, but intense flow in the lee of bed forms may also serve to break up sorted bed surface layers at flows that might otherwise produce vertical bed sorting. All three classes of dependent variable, that is, fractional transport rate, bed configuration, and bed grain size distribution, may have a strong mutual interaction, and the prediction of any one cannot be accomplished without prediction of the other two.

In the past decade, renewed interest in the transport of mixed size sediment has produced important new empirical and theoretical results. Although some of this work has included a discussion of the interaction between the grain size population of the bed and the fractional transport rates [e.g., Parker and Klingeman, 1982; Andrews and Parker, 1987; Iseya and Ikeda, 1987; Sutherland, 1987], few clearly interpretable data have been presented, a result of the difficulty of obtaining and interpreting samples of the bed surface texture and of comparing surface samples to volumetric samples of the transport or the bed sediment [Kellerhals and Bray, 1971; Day and Egginton, 1983; Church et al., 1987; Diplas and Sutherland, 1988]. The influence of bed forms on the mean fractional transport rates and vertical bed sorting has been discussed only recently [e.g., Klaassen et al., 1987; Wilcock and Southard, 1987]. This paper introduces new data taken to illustrate more clearly the interac- 
tion among all three dependent variables. Experiments were made with a single mixed size sediment for which the fractional transport rates, the bed surface grain size distribution, and the bed forms were measured. Measurements of the fractional transport rates were made when the bed surface texture and bed configuration had reached an equilibrium state. Because experimental runs were made at different flow strengths, we can investigate the adjustments among the dependent variables for different values of flow strength and total transport rate. We also took samples of the fractional transport rates at the beginning of the runs, when the bed was well mixed and planar and identical from run to run. The start-up samples permit comparison of fractional transport rates at different values of bed shear stress for constant conditions of bed surface texture and bed configuration, and they allow the adjustments among the three dependent variable groups to be clearly defined as the system changed from a fixed start-up condition to a final equilibrium condition. By taking bed surface samples for the start-up conditions, we were also able to compare samples of the equilibrium bed surface texture to equivalent samples taken at start-up, thereby avoiding the persistent and difficult problems associated with comparing surface samples to volumetric samples of the sediment bed or the transport. As a consequence, we were able to measure unambiguously the adjustment of the bed surface texture as the system adjusts toward an equilibrium condition.

To our knowledge the combination of observations presented in this paper has not been made before. Therefore these data provide a unique opportunity to describe the interaction among bed configuration, bed surface texture, and fractional transport rates. The primary goal of this paper is to demonstrate this interaction and to provide some interpretation of it that may serve as a basis for further development of a general model for mixed size sediment transport.

Because the focus of this paper is on the interaction among bed configuration, bed surface texture, and fractional transport rates as these variables undergo a mutual adjustment to reach an equilibrium state, we must also clearly define any constraints on that equilibrium state. Central to this discussion must be the concept of equal mobility which states that, for equilibrium transport conditions, the grain size distribution of the bed and the transport must be identical [Parker et $a l ., 1982 b]$. That is, bulk samples of bed and transport would be identical. If equal mobility were generally true, the direction and end result of a transport system's adjustments toward equilibrium would be largely predetermined; the adjustments discussed in this paper could focus only on the rate of adjustment and some detail of the final bed texture that would provide equal mobility for all size fractions. That we do not, in fact, find the transporting system adjusting in this way, indeed, under some conditions the system adjusts "away" from equal mobility as it adjusts toward equilibrium, is not a direct contradiction of the equal mobility hypothesis, which, as noted by Parker et al. (1982a), is strictly true only for the special case of a sediment feed flume wherein the sediment bed is used as the feed material. For the field data of Milhous [1973], Parker et al. [1982b] suggested that equal mobility provides a first approximation for the relation between the bed and transport grain size distributions. In the discussion and debate of the equal mobility concept that has followed, many have failed to appreciate that the hypothesis was not offered as physical necessity but as an approximation. It is worth pointing out that a major section of the seminal paper [Parker et al., 1982b] was devoted to observed deviations from equal mobility, including, for example, plots of the variation with bed shear stress of the fractional transport rates and $D_{50}$ of the transported sediment. Despite this, the equal mobility concept is now evolving into one that states that a transport system is not at equilibrium unless the bed and transport grain size distributions are equal. This is not the case unless one is willing to accept that a particular system operates strictly as a sediment feed flume that has adjusted to a constant sediment input. Because of the continued debate and potential misunderstanding regarding the nature and conditions for equal mobility, and because the results of this paper would be impossible if equal mobility were generally true, a second goal of this paper is to set out some constraints and conditions for the equilibrium transport of mixed size sediment.

\section{Constraints on Equilibrium Mixed Size SEDIMENT TRANSPORT}

For a transporting system to operate at equilibrium the sediment supplied to it must also leave the system at the same rate. If the transported sediment contains a mixture of grain sizes, the transport rate of each size entering the system must be identical to that leaving the system. The source of the sediment input to the system provides a particularly important constraint. The nature of this constraint can be illustrated using two end-member cases: one in which an input mixed size sediment transport rate is independently imposed on the system and one in which the input sediment load is entirely determined by the sediment and flow properties within the system. It is useful to examine these end-members because their impact on equilibrium mixed size sediment transport can be replicated exactly in laboratory flumes. Natural transporting systems contain varying proportions of these two systems, depending on the time and space scales under consideration. Here we try to define clearly the influence of the two input modes on the equilibrium transport state and develop implications for natural transport systems.

If the sediment input is independently imposed on the system, a strong constraint on the interaction between fractional transport and bed surface texture exists. If, for a given flow and bed surface, the transport rate of any fraction in the input sediment is smaller than its input rate, the system must adjust to increase the mobility of that fraction in order to achieve equilibrium, because a state of equilibrium requires that all fractions are transported at the rate with which they are input. As illustrated by the work of Parker and colleagues [e.g., Parker and Klingeman, 1982; Andrews and Parker, 1987l, less mobile fractions may become overrepresented on the bed surface, thereby increasing their mobility and permitting the system to approach equilibrium. If significant amounts of the less mobile fractions are deposited, the slopes of the bed surface and water surface may also increase, thereby changing the system hydraulics in a direction that increases the mobility of the less mobile fractions. A combination of bed surface texture and energy slope is determined by the input sediment transport rate and the inherent mobility of the different fractions in the mixture. A more particular constraint exists if the bed sediment is fed 
1a)
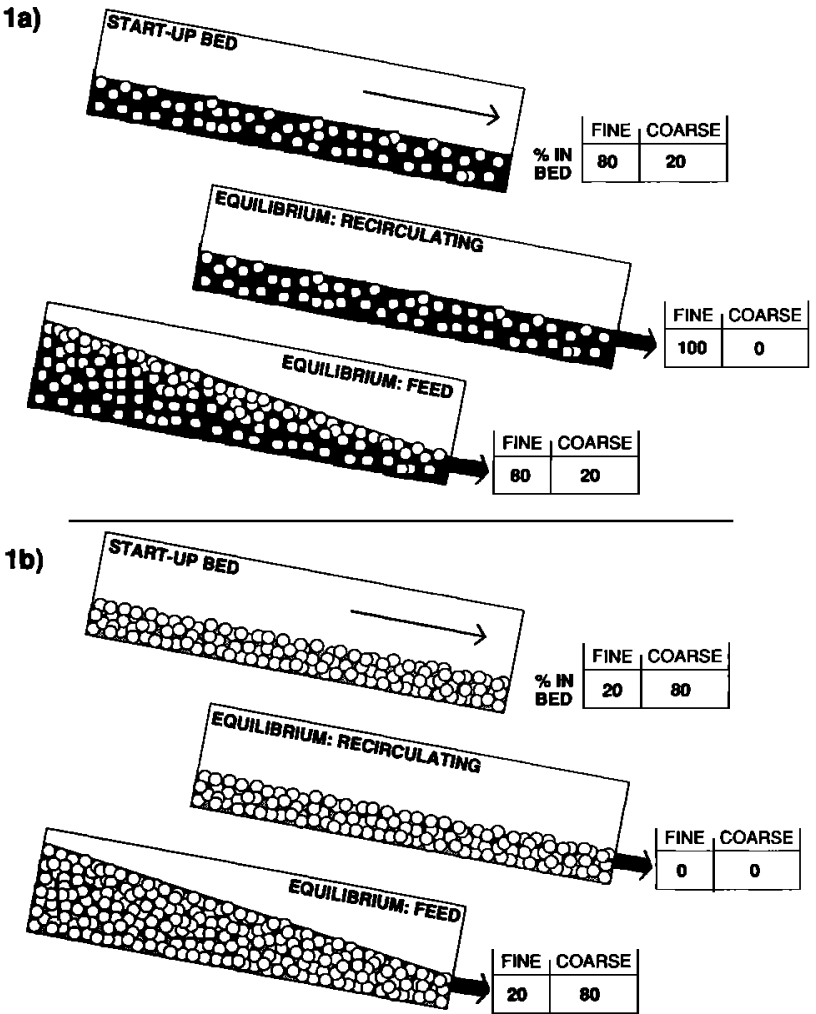

Fig. 1. Hypothetical transport experiments using two different bimodal sediment mixtures. Each mixture is run in two different flumes, one with the bed sediment fed at a constant rate (left) and the other with the sediment recirculated (right). The coarse fraction in both mixtures is assumed to be immobile at the start of the experiment, the fine fraction is assumed to be mobile. (a) Bed sediment is $80 \%$ fine and $20 \%$ coarse grains. (b) Bed sediment is $20 \%$ fine and $80 \%$ coarse material. See text for discussion of the development of contrasting equilibrium bed and transport states.

into the system at a constant rate. In this case, the grain size distribution of the bed and transport must be identical at equilibrium. This condition has been defined as equal mobility [Parker et al., 1982b; Parker and Klingeman, 1982]. As made clear in the discussion by Parker et al. [1982a], equal mobility is a requirement only under the special circumstances of equilibrium transport in a perfect feed system where the bed sediment is used as the feed material.

In a recirculating transport system the input sediment is an intrinsic product of the system itself. The input and output fractionai transport rates must still be identical at equilibrium, but the input fractional transport rates are determined solely by the flow and the sediment within the system. There is no coupling between fractional transport rates and bed surface imposed by mass conservation requirements and the inherent mobility of the different fractions.

The equal mobility constraint in a feed system can produce equilibrium transport conditions very different from those of a recirculating system, even when the initial conditions are made as similar as possible. The different equilibrium conditions arise from variations in mobility of the different size fractions and from size-dependent vertical sorting that occurs when finer grains are able to work their way beneath coarser grains in the bed. The impact of both these processes on the equilibrium transport state is illustrated with two hypothetical experiments shown in Figure 1.
Two identical flumes are used in each experiment, the only difference being that one is operated in a recirculating mode and the other in a feed mode (using feed material equivalent to the sediment bed). Both experiments involve a mixture of two size fractions, one small and the other large. For illustrative purposes we assume the small fraction to be mobile and the large fraction to be immobile under the initial flow and bed surface conditions. The sediment in the first experiment (Figure $1 a$ ) consists of $80 \%$ (by weight) fine grains and $20 \%$ coarse grains. In the recirculating system the immobile fraction simply remains on the bed in the proportion represented in the bulk mixture. If the space between coarse grains is entirely filled with fine grains, no vertical sorting can occur, and the transported sediment must consist entirely of the fine fraction. In contrast, the immobile coarse fraction in the feed flume must be deposited on the bed. To reach an equilibrium state the coarse fraction must become mobile, either by increasing its proportion of the bed surface or by building the bed slope or both. At equilibrium the coarse fraction must contribute $20 \%$ of the transported sediment. The equilibrium fractional transport rates and the composition of the bed surface are very different in these two cases, even though the same sediment bed and flow were used as initial conditions.

In the second experiment the bed sediment is changed to $20 \%$ fine grains and $80 \%$ coarse grains (Figure $1 b$ ). The fine grains are mobile and the coarse grains immobile at the start of the run, as in the first experiment. In the recirculating flume the equilibrium bed surface and transport rate are likely to not remain the same as the initial conditions, as they did in the first experiment. Vertical sorting of the sediment may occur in this case because the proportion of fine grains is small, and there is sufficient space between the coarse grains for the fine grains to work their way beneath the coarse, immobile bed surface. The final transport rate can be zero in this case if the final bed surface consists only of coarse grains. In the feed case the bed surface and bed slope must again adjust so that the equilibrium output is the same as the input. In this case the bed surface will presumably build up with a deposit of coarse grains until the shear stress is sufficient to move them. At the same time the sediment bed must become significantly overrepresented with fine grains so that the pore space is sufficiently filled and fine grains traversing the bed surface are not immediately lost to the subsurface.

Both experiments show that, even when starting with the same sediment bed and the same initial flow conditions, the adjustments between fractional transport rates and bed surface texture, and the final equilibrium condition, differ strongly between the two types of sediment input. Although the experimental conditions in the first two experiments are highly simplified, the interdependence among grain mobility, bed surface texture, and bed slope imposed by the feed system, as well as the vertical bed sorting process, should also operate in more realistic systems. Any feed system, including those with a continuous grain size distribution and all sizes in motion, are still subject to the equal mobility constraint. Vertical bed sorting should proceed more rapidly in a system where both coarse and fine fractions are in motion because the movement of coarse grains will increase the number of fine grain depositional sites.

Once equilibrium has been established in both systems, one could begin a second phase of the experiments by 
switching the feed and recirculating operational modes between the two flumes. The original feed system would have the feed input replaced by the flume output. The new sediment feed to the originally recirculating flumes would be set at the final equilibrium rate and composition achieved in the first part of the experiment. We expect that both flumes would maintain the same equilibrium conditions of hydraulics and transport. These conditions would be different between flumes because the two systems evolved to a different equilibrium condition in the first phase of the experiment. Given these conditions, a change in the input mode should not be expected to produce a change in the equilibrium developed between the bed and transport. To say that each system can maintain the equilibrium results of the other system also implies that the final equilibrium result is unique and could be achieved by either system, even if the necessary initial conditions are unknown. To our knowledge the independence of equilibrium transport and sediment supply has not been confirmed, in part due to the difficulty of arranging both types of sediment operation on a single flume.

The observation that the adjustments among transport and bed surface texture may vary between feed and recirculating systems requires careful consideration because natural transport systems contain aspects of both sediment input systems in combinations that depend largely on the time and space scales under consideration in any particular problem. For example, transport over long time periods through an entire river basin or across the continental shelf is clearly a feed system, although in these cases transport will not generally be at equilibrium. Many transport problems, or models, operate at a much smaller scale. A typical problem might involve prediction of sediment transport rates over a period of minutes or hours, given the bed grain size distribution and the flow conditions. This problem involves more of a recirculating component and approaches an entirely recirculating state if the bed sediment is relatively consistent over distances comparable to the distance traveled by the sediment under the time period of interest. In such a case the transport system may reach an equilibrium state over a period of hours, and the problem of predicting the transport, given the bed and flow properties, would be exactly modeled by a recirculating flume.

The purpose of this section is not to advocate feed or recirculating simulation of natural transporting systems or to show that natural systems contain either input component in some known proportion. Rather, this section is intended to present the constraints on equilibrium sediment transport provided by these two end-member transport systems and to draw implications regarding natural transport. The hypothetical experiments were presented to illustrate that equilibrium transport conditions for the two input systems are, in general, not equivalent and can be very different, even when starting from initial conditions that are as similar as possible. Once equilibrium is established, the two input modes should maintain the equilibrium transport conditions produced by either input mode.

An additional observation concerning equilibrium mixed size sediment transport contributes to this discussion. Many mixed size sediments with unimodal or weakly bimodal grain size distributions operate close to equâl mobility in perfectly recirculating systems in the laboratory [Wilcock and Southard, 1988]. Nearly equal mobility in a recirculating system is not the result of a constraint imposed by the sediment input but reflects a balance between mixture effects on fractional transport rates (grain hiding/exposure, relative bed roughness) and vertical sorting. One can imagine another experiment similar to those in Figure 1 in which a continuous grain size distribution is used and all fractions are mobile. The observation given above is that both flumes would evolve to essentially the same equilibrium transport conditions. This observation, if general, is a disadvantage for determining how natural systems operate: if the mobility differences between fractions were enormous, it would be obvious if a natural system had a predominantly feed or recirculating character as it adjusted to a near-equilibrium state. However, the fact that many mixed size sediments appear to operate naturally near equal mobility is also an advantage in that the advantages of both flume methods, and the concepts behind them, may be applicable to natural transporting systems.

The direction in which the transport and bed surface texture adjust in approaching an equilibrium condition can be very different in feed and recirculating systems. This implication directly concerns the results of this paper. In a feed system the adjustment is forced to an equal mobility condition. In a recirculating system this constraint does not exist, and the adjustment is determined by the bed sediment, the flow, the mobility of the different fractions, and the vertical sorting. If only the sediment bed and flow conditions are known, the final equilibrium condition cannot be determined without knowledge of the type of input mode. The experiments reported in this paper use a recirculating system. It should be clear from the preceding discussion that the adjustments among transport and bed surface texture reported in this paper are not subject to any particular constraint due to the nature of the input sediment.

A second important implication regarding natural transport conditions concerns the nature of equilibrium transport: except for perfect feed systems in which the bed sediment is used as input, a transporting reach need not achieve equal mobility to achieve equilibrium. The recirculating experiments in Figure 1 reached an equilibrium state for the flow and bed sediment involved, but the equilibrium grain size distribution of the transport and bed were considerably different; the equilibrium system was not close to equal mobility. Natural transport systems may approach such a condition of equilibrium but nonequal mobility. Laboratory observations suggest that equilibrium is reached in a period of a few hours for recirculating systems [Wilcock, 1987]. When natural flow conditions are constant for a similar period and the bed grain size distribution is relatively consistent over distances corresponding to the mean transport of sediment during that period, a natural transport system can achieve a short-term equilibrium between the sediment bed and prevailing flow. This short-term equilibrium is best modeled by a recirculating system and corresponds well to the typical transport problem in which the initial conditions of bed sediment and flow are given and the sediment transport is to be predicted.

The observation that the transport grain size distribution is close to the bed grain size distribution in some field data led to the original formulation of the equal mobility hypothesis [Parker et at., [982b]. Because equal mobility can be strictly true only for a perfect feed system, the observation of nearly equal mobility in the field would support the concept that sediment feed flumes provide a good approximation of 
TABLE 1. Hydraulic and Transport Parameters

\begin{tabular}{|c|c|c|c|c|c|c|c|c|}
\hline \multirow[b]{2}{*}{ Run } & \multirow{2}{*}{$\begin{array}{c}\text { Mean } \\
\text { Velocity, } \\
\mathrm{cm} / \mathrm{s}\end{array}$} & \multirow[b]{2}{*}{ Slope } & \multirow[b]{2}{*}{$\begin{array}{l}\text { Deplh, } \\
\text { cm }\end{array}$} & \multicolumn{2}{|c|}{$\begin{array}{l}\text { Bed Shear } \\
\text { Stress }\end{array}$} & \multicolumn{2}{|c|}{ Total Transport Rates } & \multirow[b]{2}{*}{ Bed Configuration } \\
\hline & & & & $\begin{array}{l}\tau_{0} \\
\mathrm{~Pa}\end{array}$ & $\tau_{0} / \tau_{\mathrm{c}}$ & $\begin{array}{c}\text { Initial } \\
q_{b}, \mathrm{~g} / \mathrm{ms}\end{array}$ & $\begin{array}{l}\text { Equilibrium } q_{b}, \\
\mathrm{~g} / \mathrm{ms}\end{array}$ & \\
\hline 1 & 43.5 & .00109 & 11.25 & 1.03 & 1.14 & 0.167 & 0.0159 & plane \\
\hline 2 & 47.5 & .00125 & 11.06 & 1.17 & 1.29 & 0.342 & 0.468 & plane \\
\hline 3 & 49.9 & .00144 & 11.26 & 1.26 & 1.40 & 2.50 & 1.96 & two-dimensional dunes \\
\hline 4 & 53.4 & .00184 & 11.22 & 1.36 & 1.51 & 9.94 & 4.50 & two-dimensional dunes \\
\hline 5 & 55.9 & .00214 & 11.25 & 1.56 & 1.70 & 7.88 & 9.69 & two-dimensional dunes \\
\hline 6 & 65.5 & .00280 & 11.04 & 2.17 & 2.41 & n.a. & 29.7 & two-dimensional dunes \\
\hline 7 & 72.9 & .00330 & 10.93 & 2.78 & 3.09 & n.a. & 59.4 & $\begin{array}{l}\text { two-dimensional to three- } \\
\text { dimensional dunes }\end{array}$ \\
\hline
\end{tabular}

quasi-equilibrium field transport or that natural systems have a predominantly feed character. The observation that equilibrium mixed size sediment transport in recirculating systems also produces nearly equal mobility suggests that either kind of flume may represent natural systems, which contain a combination of both input modes. The choice of input mode should depend on the specific questions to be addressed. The goal of this paper is to examine the free adjustment among fractional transport rates, coarse surface layers, and bed configuration, for which the unconstrained recirculating method provides a clear and efficient arrangement. For a given bed sediment, flow depth, and discharge we examine the adjustments among fractional transport rates, bed surface texture, and bed configuration.

\section{Experimental Methods}

We report here on seven experimental runs made with a single sediment. General hydraulic and transport parameters for each run are given in Table 1. The sediment had a mean size of $1.83 \mathrm{~mm}$ and a sorting of 0.99 , if grain size is expressed in $\phi$ units $\left(D_{84} / D_{16}=4.0\right)$. The grain size distribution was lognormal. The cumulative grain size distribution of the bed sediment is given in Figure 2. The sediment consisted almost entirely of quartz and near-quartz density minerals, and the density used in transport computations is $2.65 \mathrm{~g} / \mathrm{cm}^{3}$. The central portions of the sediment mixtures are slightly more angular (subangular versus subrounded) and of lower sphericity than the tails.

\section{Apparatus}

The experiments were made in a flume with a rectangular channel $23 \mathrm{~m}$ long, $0.6 \mathrm{~m}$ wide, and $0.3 \mathrm{~m}$ deep, with transparent sidewalls. Water and sediment were recirculated separately. The upstream $6 \mathrm{~m}$ of the channel contained a false bottom at the same elevation as the sediment bed. Sand 1.83-2.00 $\mathrm{mm}$ in diameter (the mean size of the sediment mixture) was glued to the downstream $4.9 \mathrm{~m}$ of the false bottom to allow the boundary layer to develop before it reached the movable bed. The $16.2-\mathrm{m}$ working section of the bed ended in a sediment trap that extended $25 \mathrm{~cm}$ in the flow direction and across the full width of the flume. All the transported sediment fell into the trap and was returned, with a small discharge of water, to the head of the channel by an air-driven diaphragm pump through a $2.5 \mathrm{~cm}$ ( 1 in.) tube. The trap caught virtually $100 \%$ of the passing sediment.

Channel slope was continuously adjustable. The flow passed into the tailbox with no free overfall, so the volume of water in the flume determined the mean depth of flow. Uniform flow was maintained by adjusting the flume slope. Water discharge was determined from the calibrated head loss in a straight section of the return pipe. Mean flow depth and water surface slope were determined from water surface and bed surface elevations read with a point gage mounted on a cart that traversed rails parallel to the floor of the channel.

\section{Transport Sampling}

Sediment transport was sampled by passing the watersediment mixture in the sediment return system through a $20.3 \mathrm{~cm}$ ( 8 in.) sieve that trapped the sediment and allowed the water to return to the headbox through the diaphragm pump. This was achieved by closing a valve in the sediment return line between the trap and the pump and allowing the water-sediment mixture to flow under gravity through a flexible tube into a large funnel that was itself connected to the sediment return system between the diversion valve and the pump. Sediment could also be returned to the recirculation system via the sample funnel, so that sampled sediment could be replaced.

During sampling periods all of the transport was measured volumetrically by emptying the sample from the sampling sieve into a graduated cylinder. While a second sampling sieve was filling, the volume of sediment in the graduate was measured, and the sample was returned to the recirculation system. During the sampling period all of the transported sediment was sampled, except at very high transport rates when we were not able to keep pace and could sample only $30 \mathrm{~s}$ out of every minute. The duration of the individual samples varied from 30-s subsamples to 1-hour samples of low transport rates. Some volumetric transport samples were not returned but saved to be dried, weighed, and sieved at $1 / 4-\phi$ intervals. The retained samples were replaced by equal volumes of sediment; usually this replacement sediment was material sampled earlier in the same run or during the previous run, so its grain size distribution was not substantially different from the sampled sediment. If bed forms were present, transport rates were computed only for whole numbers of bed forms. The number of bed forms sampled varied from one (150-min. sample period) to 17 . The mean grain size distribution of the transported load was determined as a weighted mean for many samples taken over individual bed forms. 


\section{Bed Surface Texture}

Samples of the bed surface were taken using two different techniques. The first involved spray painting an area of the bed $12.7 \mathrm{~cm}$ in diameter with a mixture of paint and fine magnetite. Surface grains (defined as those having any paint on them) were removed from the sample with a strong hand magnet. Some additional separation was necessary to remove unpainted grains that had adhered to painted grains during removal of the sample from the bed. This technique [Wilcock and Stull, 1989] was developed because manual removal of painted grains finer than 1 or $2 \mathrm{~mm}$ was found to be impossibly tedious. The second sampling method involved pressing a circular cylinder filled with moist clay onto the bed. The cylinder was the same size as that used as a mask for painting the bed. The clay technique has been used by numerous authors [e.g., Dhamotharan et al., 1980; Kuhnle and Southard, 1988]. We collected samples using both methods and found them to give comparable results, although the magnetic sampler appears to recover a slightly greater percentage of grains from the middle and coarse portions of the grain size distribution. The slight difference between the two samplers is presumably due to the inability of the clay sampler to pick up coarser grains that have only a small amount of clay adhering to them. We prefer the magnetic paint technique because it allows direct observation of the sample and thereby provides an accurate check that all grains on the surface have been sampled and that the sample contains only those grains that were on the bed surface.

A considerable controversy exists as to whether areal surface samples, such as those collected by the paint or clay techniques, may be compared with samples taken volumetrically, such as by removing a predetermined volume of sediment from the bed (see Church et al. [1987], and accompanying discussions and reply, for a recent summary of the problem). The essence of the problem is whether the proportion in each fraction must be multiplied by the factor $1 / D$, as originally proposed by Kellerhals and Bray [1971] and recently confirmed by Church et al. [1987]. A number of authors have found the $1 / D$ correction to give results that are biased toward the finer sizes [e.g., Proffit and Sutherland, 1980]. Diplas and Sutherland [1988] provide theoretical and experimental support for a correction factor based on $D^{1 / 2}$. Unfortunately, the controversy regarding correction factors for surface samples has become intermeshed with the issue of whether the surface of a mixed size sediment bed may coarsen during equilibrium transport [e.g., Parker et al., $1982 b ;$ Day and Egginton, 1983]. Because the adjustment of the bed surface texture is of direct importance to this paper, and because we do not have a definitive solution to the problems of correction techniques for bed surface samples, we have chosen to sidestep the problem by making comparisons only among samples taken with identical techniques. Transport samples are compared only with each other and use the volumetric grain size distribution of the sediment mixture as a reference. Surface samples are compared only to other surface samples and then only to samples taken with the same sampling device (clay or paint). These samples use as a reference the mean of five surface samples taken with each method from the bed at its start-up condition. Although limiting ourselves in this fashion prevents us from making direct comparisons between particular transport and bed surface grain size distributions, it does allow us to make unambiguous comparisons of the different transport and bed surface grain size distributions, which is our intention in this paper.

\section{Procedure}

The sediment bed was mixed and screeded to a plane bed $7 \mathrm{~cm}$ thick before each run. A mixing procedure was followed in which the sediment was first homogenized by hand in half-meter segments along the channel, then half the sediment in each segment was exchanged with that of other segments following a predetermined recipe, and finally the sediment was rehomogenized in each segment. The flume was then filled slowly with hot and cold water to achieve a temperature between $24^{\circ}$ and $26^{\circ} \mathrm{C}$. This temperature was maintained during runs by adding small volumes of hot or cold water to the flume; a constant water volume (and hence flow depth) was maintained with an overflow pipe in the tailbox. To produce an initial sediment bed that was consistent from run to run, the flume was next run for $30 \mathrm{~min}$. at a mean velocity of $41 \mathrm{~cm} / \mathrm{s}$ and a flow depth of $11.2 \mathrm{~cm}$. This flow produced a very low transport rate $(\ll 0.01 \mathrm{~g} / \mathrm{ms})$ that was just sufficient to move grains (of any size) that were left in particularly unstable positions by the screeding process. Following this preparation, the run was immediately begun by adjusting the flume slope and discharge to the desired values. Previous experience with the flume and sediment allowed the slope to be set immediately to the value necessary for uniform flow at the start of the run. One run consisted only of the 30-min. preparatory flow, after which the flume was drained and samples of the bed surface were taken.

Sampling of the transport rate began five min. after the start of the run. The duration of these samples varied from 1 to $30 \mathrm{~min}$., depending on the transport rate. No bed forms were present during any of the initial samples included in this paper. Measurements of equilibrium flow and sediment transport were made only after long-term steady transport became established. In previous experiments [Wilcock and Southard, 1988], equilibrium was judged by the absence of long-term variability in the flow properties (related to the development of a stable bed configuration) and in the size distribution of the transported sediment (related to the development of a stable grain size distribution on the bed surface). To avoid any significant impact on the sediment bed and transport rates during the run, intermediate samples were not taken, and final equilibrium was assumed to have been established when the run duration was greater than or equal to sufficient values in previous runs. While the transport sampling was underway, the water surface elevation was read, and the head loss in the return pipe was measured for later conversion to water surface slope and discharge. After each run the flume was drained, the bed was described, a profile of the bed elevation along the flume centerline was made, and bed surface samples were taken.

\section{ExPERIMENTAL RESUlTS}

\section{Initial Conditions}

The grain size distributions of the transport samples taken at the beginning of each run are shown in Figure 2. Data for the range $1.0<\tau / \tau,<1.7$ are available, where $\tau$ is the mean bed shear stress and $\tau_{c}=0.9 \mathrm{~Pa}$ was determined as the value 


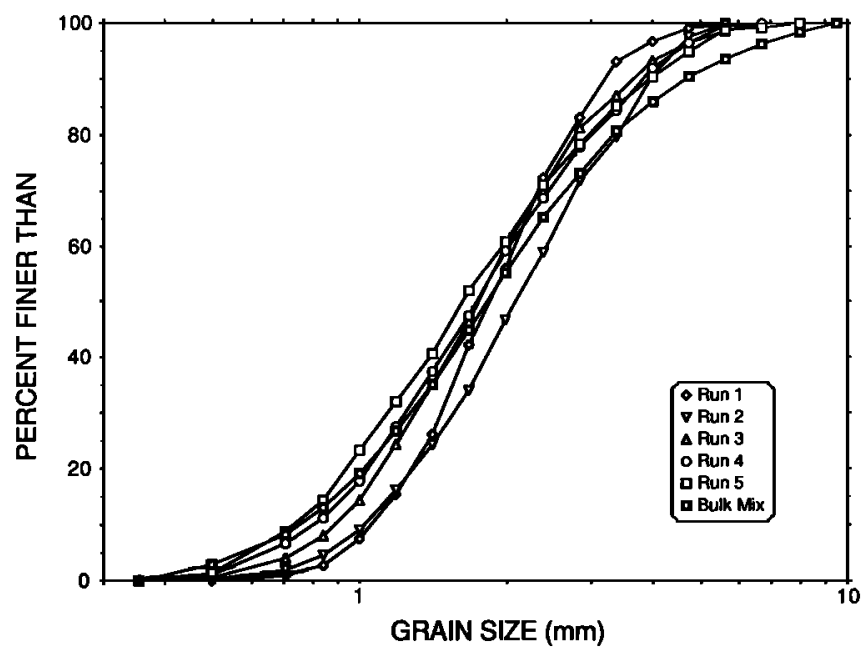

Fig. 2. Grain size distribution of transport samples taken at the beginning of five flume runs. The size distribution of volumetric samples of the bulk sediment mix is given as a reference.

of $\tau$ where the total transport rate approaches zero [Wilcock, 1988]. At the lowest transport rates the finer fractions of the sediment mixture are underrepresented in the transport compared to their proportion in the bed sediment mix. The proportion of finer fractions in transport increases with shear stress until it is essentially equivalent to the bed mixture at $\tau \geq 1.5 \tau_{c}$. The coarser portion of the sediment mixture is also underrepresented in the transport at the lower transport rates, and its proportion of the transported sediment increases with shear stress but is still underrepresented at the higher transport rates measured. These results show that near incipient motion the finer and coarser size fractions are less mobile than the central size fractions. This difference in mobility decreases with $\tau$, disappearing altogether for the finer fractions, but not the coarser fractions, at the higher values of $\tau / \tau$, we measured. The data available do not make clear whether the coarser fractions would achieve equal mobility at a higher shear stress, although the trend of the data point in that direction. Because the bed surface is the same for each run in Figure 2, it may be seen clearly that the mobility of individual size fractions varies with grain size and that this size-dependent variation in mobility itself depends on the shear stress acting on the bed, with the proportion of both finer and coarser fractions increasing in the transported sediment at higher shear stresses.

\section{Equilibrium Conditions}

Fractional transport rates. The grain size distributions of transport samples taken after the transport reached equilibrium are shown in Figure 3. The variation of the transport grain size distribution with bed shear stress is more complicated than in the start-up case. At the run nearest incipient motion the proportion of the finer fractions is very close to that in the bed. As the shear stress increases, the proportion of the finer fractions first decreases, but then, above $1.5 \tau_{\text {, }}$, the proportion of the finer fractions increases and slightly exceeds that of the bulk sediment mix at the two highest flows tested. The coarsest fractions are underrepresented in the run closest to incipient motion. As $\tau$ increases, the proportion of coarse fractions decreases until about $1.3 \tau_{c}$, then increases with further increase in $\tau$ and approaches, but

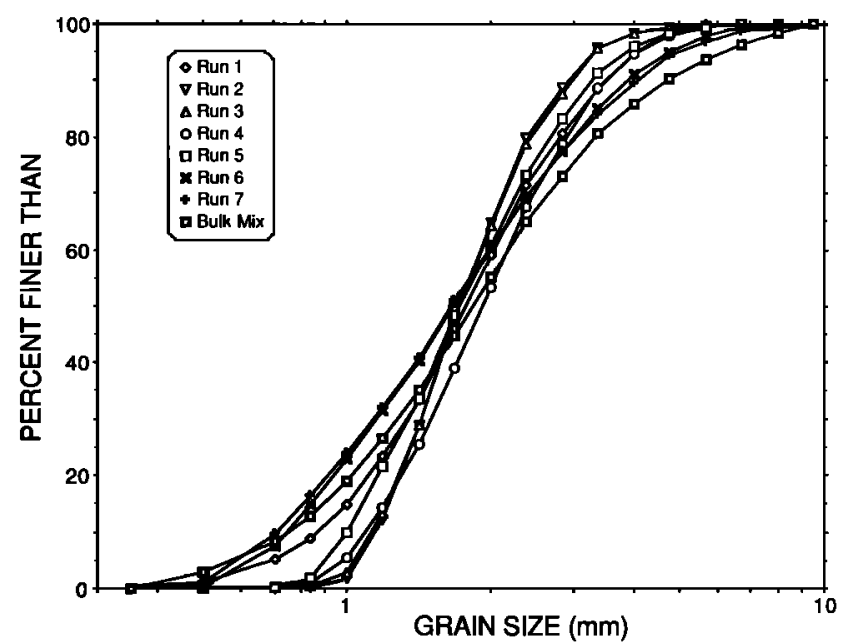

Fig. 3. Grain size distribution of transport samples taken at the end of all flume runs, when the bed surface and bed configuration had reached an equilibrium state. The size distributıon of volumetric samples of the bulk sediment mix is given as a reference.

does not reach, equal mobility even at the highest shear stresses tested. As in the start-up case, the mobility of the various fractions changes with bed shear stress, although in the equilibrium case the bed surface texture also varies from run to run

Figures 2 and 3 allow a comparison of transport grain size distributions between a well-mixed sediment bed with a constant grain size distribution and a bed allowed to reach an equilibrium bed surface texture. In both cases there is a general increase with bed shear stress in the proportion of fine and coarse fractions in transport. The finer fractions reach equal mobility in both cases, although at a higher shear stress when the bed has reached an equilibrium bed surface texture. The coarse fractions in both cases do not reach equal mobility over the range of $\tau / \tau$, we measured. The relative mobility of the different sizes in a mixture clearly varies with bed shear stress, whether over a constant bed surface grain size distribution or over a bed surface texture that is allowed to adjust to an equilibrium state. The equilibrium samples differ from the start-up samples in that the proportion of both fine and coarse fractions decreases with increasing shear stress for the runs immediately above incipient motion. The implications of this observation will be discussed further, once the adjustments of the other dependent variables are presented.

An alternative presentation of the transport grain size distributions is given in Figure 4, which plots the fractional transport rates as a function of grain size. Fractional transport rates are computed as $q_{b i}=\left(p_{l} / f_{l}\right) q_{b}$, where $p_{l}$ is the proportion of each fraction in transport, $f$ is its proportion in the bulk bed sediment mix, and $q_{h}$ is the total transport rate. Because the value of $q_{b}$ is the same for each fraction in a run, Figure 4 gives the transport grain size distribution in the form of $p_{1} / f$, scaled by the total transport rate. Figure 4 provides a very clear presentation of the shift in transport grain size distribution with increasing shear stress and transport rate and makes the proportions of the middle size fractions clearer.

Bed surface grain size distribution. Samples of the bed surface texture were taken following each run. When bed forms were present, the samples shown here were taken 


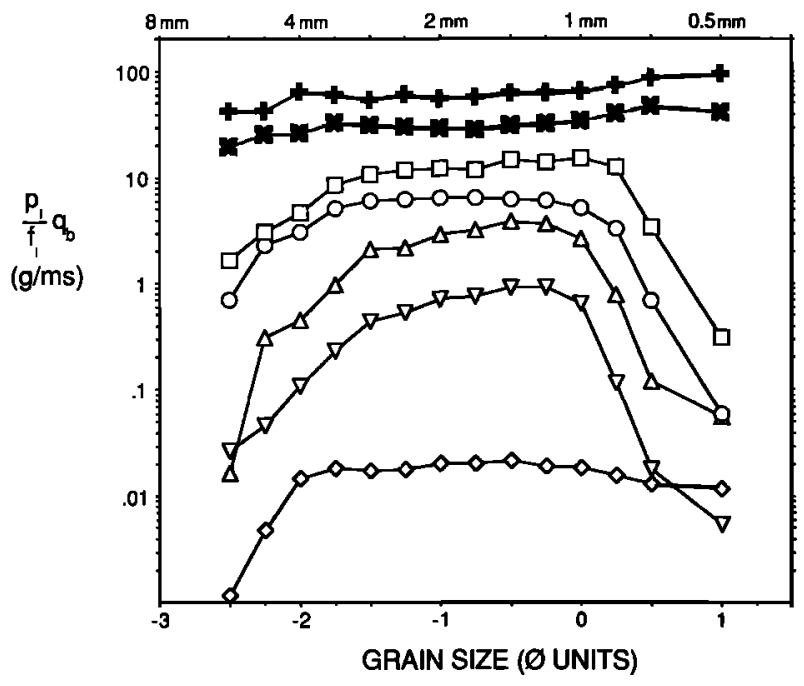

Fig. 4. Fractional transport rates at the end of all flume runs. Because $q_{b}$ is a constant for each fraction in a run, the trends represent the grain size distribution of the transport in the form $p_{l} / f_{1}$. Plot symbols same as Figure 3.

from the bed form troughs. The troughs form the exposed portion of the surface over which the bed forms move and therefore represent the surface on which, or through which, size-dependent exchange of sediment may occur as the bed adjusts toward equilibrium.

Figure 5 presents cumulative grain size distributions for magnetic paint samples taken from runs 1 through 5. Each grain size distribution curve represents the mean of a number of samples, which is shown in the figure legend. The bed surface grain size distribution for the 30 -min. start-up run is shown as a reference. The fine and coarse fractions show a similar and consistent increase in proportion with increasing bed shear stress, although the proportions of the fine and coarse fractions present in the bed are different. The finer

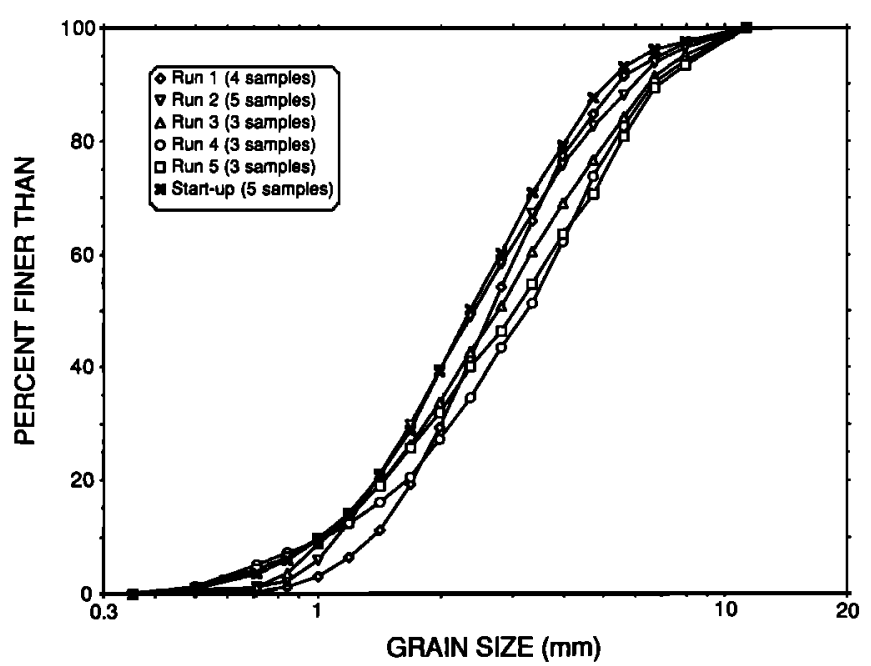

Fig. 5. Grain size distribution of equilibrium bed surface samples taken with the magnetic paint sampler at the end of five flume runs. When bed forms were present, the surface sampled was the bed form trough. The mean size distribution of magnetic paint samples taken from the start-up bed is given as a reference. The number of samples used to produce the plotted grain size distribution is shown in the figure legend.

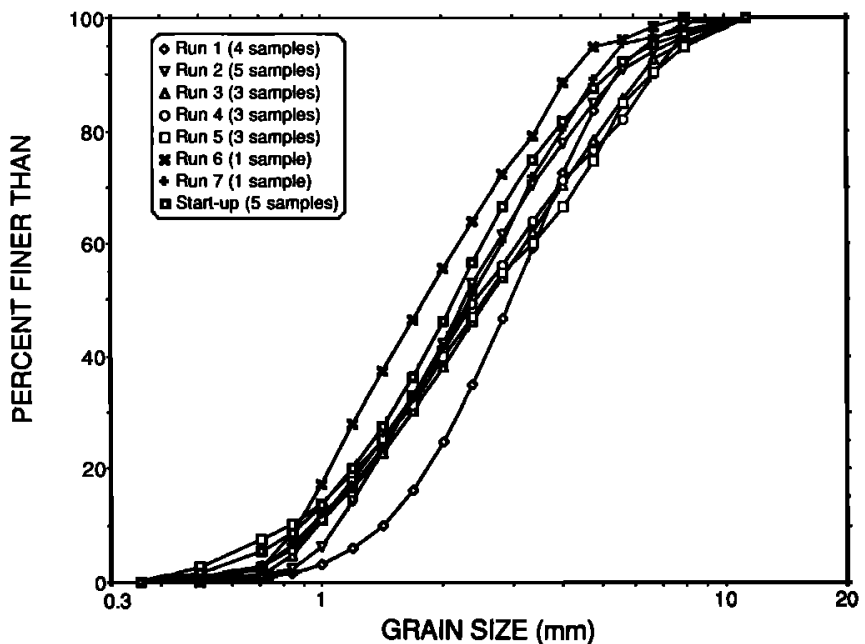

Fig. 6. Grain size distribution of equilibrium bed surface samples taken with the clay sampler at the end of all flume runs. When bed forms were present, the surface sampled was the bed form trough. The mean size distribution of clay samples taken from the start-up bed is given as a reference. The number of samples used to produce the plotted grain size distribution is shown in the figure legend.

fractions are underrepresented with respect to the start-up condition at the lowest flows and then approach the wellmixed start-up condition as the flow increases. In contrast, the proportion of coarse fractions on the bed surface after the first run is essentially identical to the start-up condition. As the flow increases, the coarse fraction becomes increasingly overrepresented with respect to the start-up condition. Previous discussions of the development of an equilibrium coarse surface layer have been criticized because bed surface samples were compared to the bulk mix, thereby involving a comparison between areal and volumetric bed samples [Parker, 1980; Parker et al., 1982b; Day and Egginton, 1983]. Because of this sampling problem the actual existence of an equilibrium coarse surface layer was questioned [Day and Egginton, 1983]. Because the same sampling method was used for both the start-up and equilibrium samples, Figure 5 clearly shows that the bed surface layer coarsens during adjustment toward equilibrium.

The magnetic paint method had not been devised at the time runs 6 and 7 were made, although individual samples of the bed surface were taken with a clay sampler. Figure 6 presents cumulative grain size distributions for these individual samples, as well as the mean of clay samples taken after the five runs shown in Figure 5. The trends for the lower five runs are similar to, if more scattered than, those in Figure 5, but the equilibrium bed surface texture in runs 6 and 7 is considerably finer and similar to the well-mixed start-up bed surface. Because only single samples were taken of the bed after these two runs, the exact grain size distributions are less accurate than those for the weaker-flow runs. The surface textures for runs 6 and 7 do, however, appear to represent faithfully the equilibrium bed condition, which we observed to be distinctly finer at the strongest flows and not particularly different from the bulk sediment mixture.

Figures 5 and 6 both show that the proportions of fine and coarse fractions in the equilibrium bed surface texture increase with flow strength up to roughly $2 \tau_{c}$. With increasing $\tau$, the fine fractions approach a proportion equivalent to that 


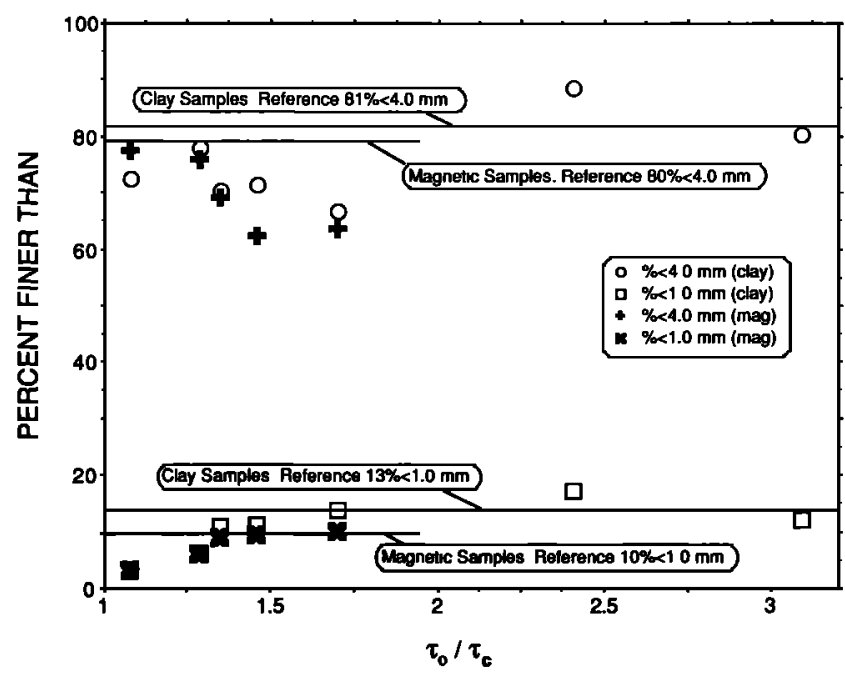

Fig. 7. Variation in equilibrium bed surface texture with $\tau / \tau_{\text {, }}$, the ratio of mean bed shear stress to the critical shear stress for incipient motion of the sediment bed. Plot symbols represent the percent finer than 4 and $1 \mathrm{~mm}$ for both clay and magnetic paint samples. Corresponding values for the start-up conditions are provided as a reference and are represented by horizontal lines.

of the well-mixed start-up bed, while the coarse fractions become increasingly overrepresented. At $\tau>2 \tau$, the coarse surface layer is completely broken up; both fine and coarse fractions are present on the bed surface in a proportion close to that of the well-mixed bed. Figure 7 , which shows the percent in the bed surface samples finer than 4.0 and $1.0 \mathrm{~mm}$, illustrates these points more clearly. The reference lines correspond to the mean values determined from five samples of the start-up bed surface using the magnetic and clay samplers. The proportion of grains finer than $1.0 \mathrm{~mm}$ increases from around $3 \%$ near incipient motion to the wellmixed condition ( $10 \%$ for the magnetic samples, $13 \%$ for the clay samples) at $\tau<2 \tau_{c}$. The proportion of grains coarser than $4.0 \mathrm{~mm}$ increases from near start-up conditions ( $21 \%$ for the magnetic samples; $19 \%$ for the clay samples) close to incipient motion to roughly $35 \%$ at $\tau \approx 1.4 \tau_{\tau}$. At the highest flow strengths the proportion of these coarse grains drops to less than $20 \%$, which is comparable to the reference value within the error associated with these two individual samples of the bed surface texture.

Bed configuration. Figure 8 presents the dimensions of the equilibrium bed forms for each run with bed forms in Table 1 plus additional runs made with the same sediment mixture. The bed was planar in the lowest runs. Above $\tau \approx$ $1.3 \tau_{c}$, long, low dunes formed with relatively straight, flowperpendicular crests. The bed form crests became more irregular in shape and orientation at the highest flow strengths, although they remained essentially flow perpendicular at all flows. The variability in bed form height and trough depth also increased with flow strength. In the strongest flows, bed form height commonly varied from 1 to $6 \mathrm{~cm}$ across the $60 \mathrm{~cm}$ width of the flume. The spacing of the bed forms decreased with flow strength from almost 200 to $80-100 \mathrm{~cm}$. The height of the bed forms increased with flow strength from approximately $D_{m}(0.185 \mathrm{~cm})$ at low flows to $8 D_{m}(1.5 \mathrm{~cm})$ at the highest flows. The changes in spacing and height caused the bed forms to increase in steepness, with the ratio of spacing to height decreasing to a fairly constant value of $80-90$ at $\tau>1.5 \tau$.

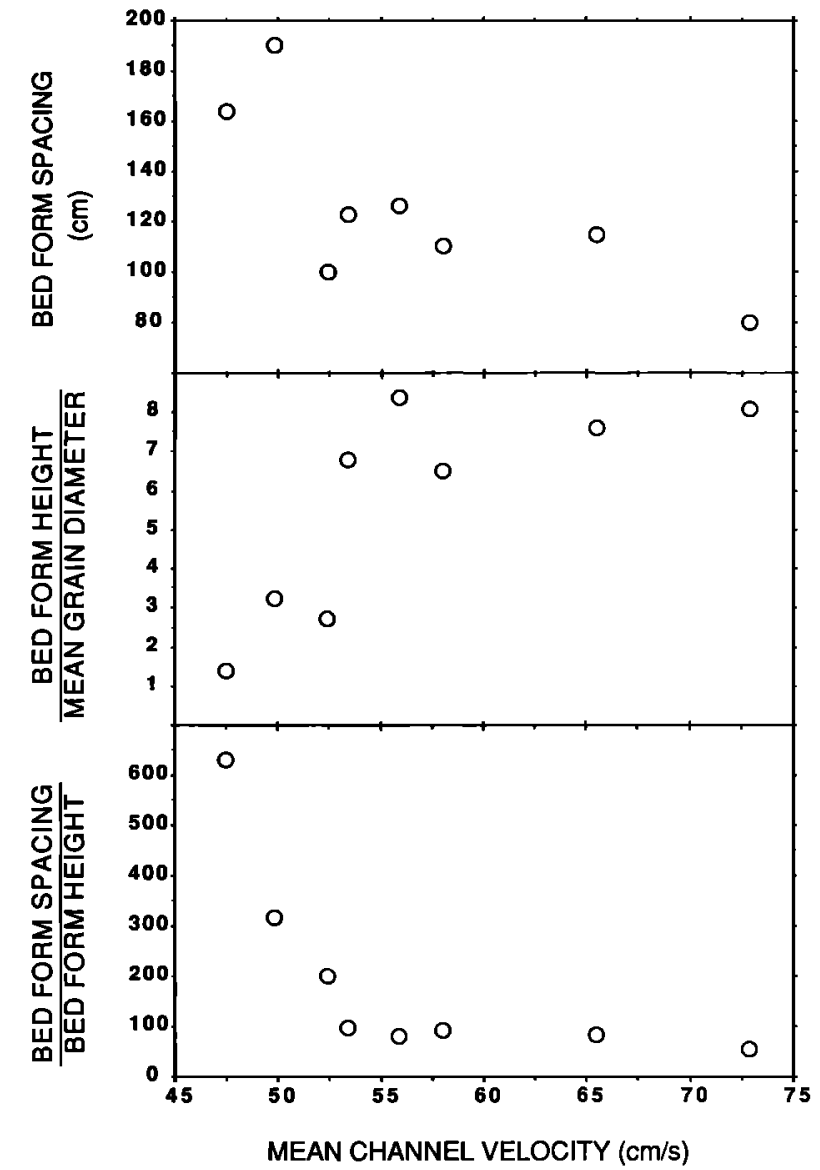

Fig. 8. Bed form spacing, height, and height-to-spacing ratio for all runs with bed forms. For better coverage the plot includes results from three runs with the same sediment that are not discussed in this paper.

\section{Adjustments of Fractional Transport Rates ANd Bed Surface TeXture}

As shown in Figures 9 and 10, most of the apparent adjustment between the fractional transport rates and the bed surface texture occurs in the finest and coarsest fractions. Figure 9 presents the initial (solid symbols) and equilibrium (open symbols) fractional transport rates for runs $1-5$, as a function of grain size. Again, because $q_{b}$ is a constant for each fraction in a run, plots of $q_{b}$ provide a grain size distribution in the form of $p_{t} / f$, versus grain size. The equilibrium fractional transport rates for runs 6 and 7 are also shown in Figure 9. No initial transport samples were taken for these runs. Figure 10 presents the initial and equilibrium bed surface grain size distributions for all runs. Magnetic samples are used for runs 1-5; clay samples for runs 6 and 7. The initial bed surface samples shown are the mean of five magnetic samples for runs $1-5$ and the mean of five clay samples for runs 6 and 7 . The equilibrium bed surface grain size distributions for runs 6 and 7 represent only a single clay sample for each run, so more error may be associated with these two equilibrium distributions than with the equilibrium distributions in runs 1-5, which represent the means of several bed samples.

Figure 11 presents the variation with $\tau / \tau_{c}$ of the percent finer than 1 and $4 \mathrm{~mm}$ in both initial and equilibrium transport samples. It is similar to Figure 7 in that it illustrates 


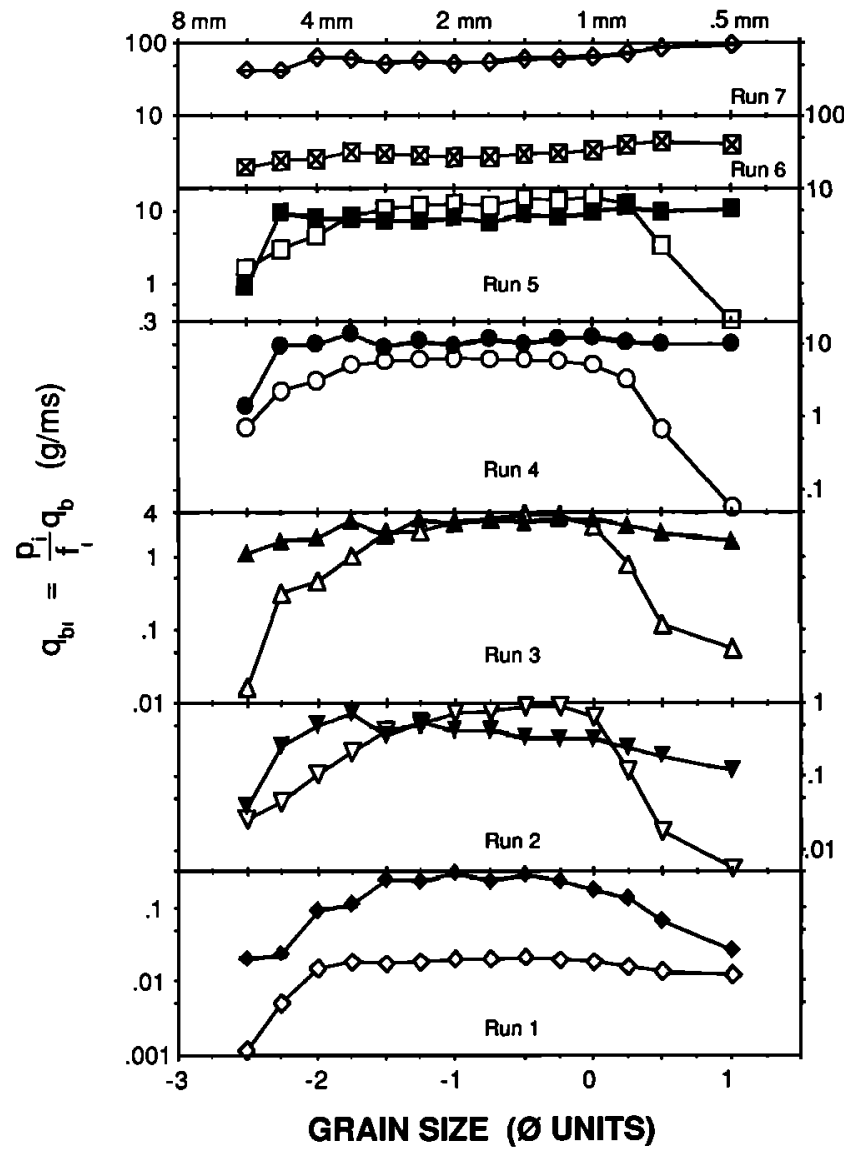

Fig. 9. Fractional transport rates for initial and equilibrium conditions in all runs. Solid symbols are initial fractional transport rates; open symbols are equilibrium fractional transport rates. Transport rates were not sampled at the beginning of runs 6 and 7; initial fractional transport rates for these runs may be assumed to be close to equal mobility and hence close to the final fractional transport rates.

the variation of the amount of fine and coarse sediment in transport with both shear stress and time.

\section{Coarser Fractions}

Runs 1-5. As the bed and transport adjusted toward equilibrium in these runs, the proportions of the coarse fractions in transport and in the bed surface adjusted in opposite directions. The percent of coarse fractions in transport decreased with time for these runs (Figures 9 and 11). The proportion of coarse fractions present on the bed surface increased with time (a coarse surface layer developed; Figures 7 and 10). This result cautions against the simplistic conclusion that an increase in the representation of a particular fraction on the bed surface represents a corresponding increase in its fractional transport rate. The degree of this counterintuitive adjustment decreases with $\tau$. That is, the extent of development of a coarse surface layer increases with $\tau$, and the time-dependent decrease of coarse fractions in transport decreases with $\tau$. This suggests that the cause of the seemingly contrary adjustment of coarse fractions on the bed surface and in transport is more prevalent as $\tau$ approaches $\tau_{\text {c }}$.

Our explanation involves two points: the proportion of immobile grains on the bed surface and the depth of the bed

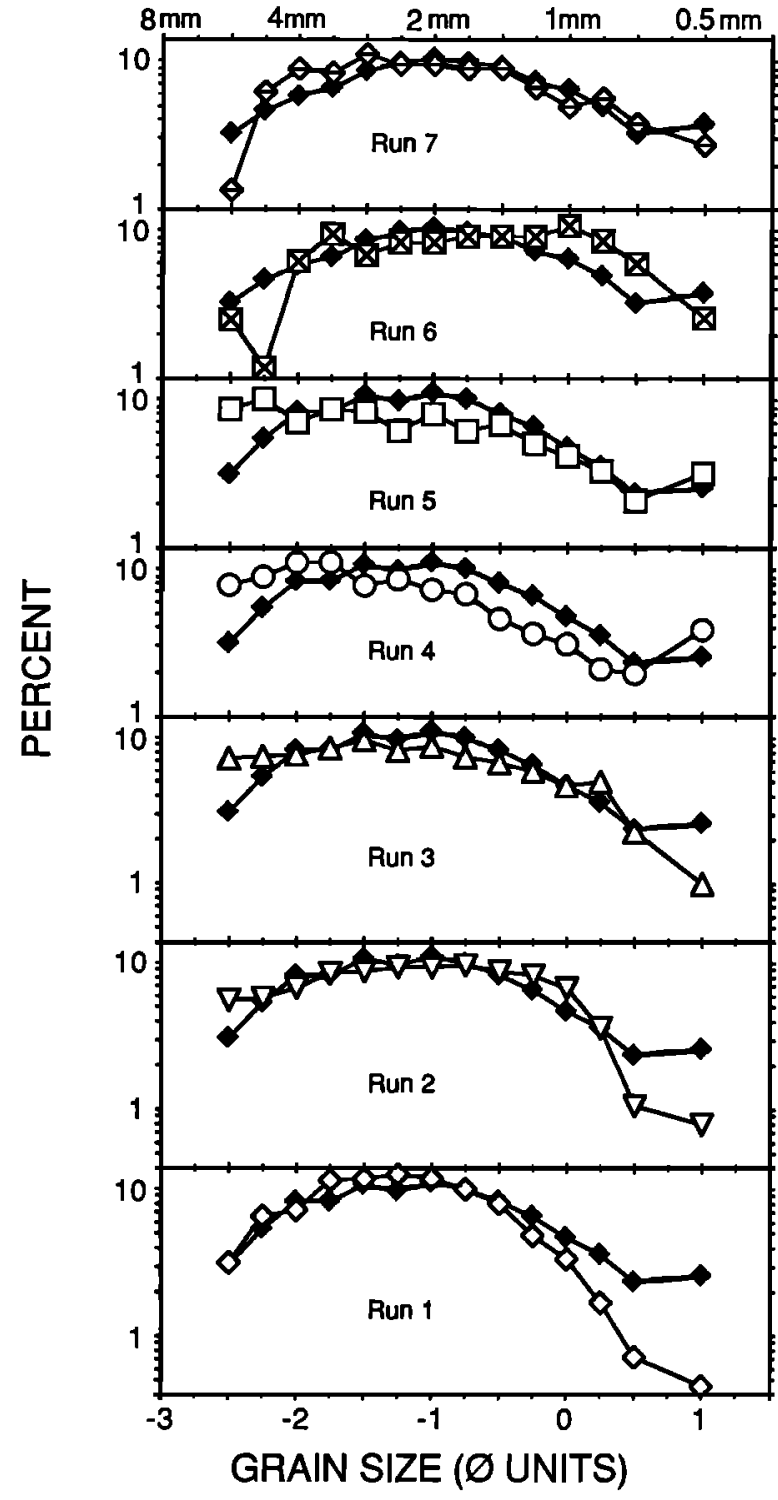

Fig. 10. Bed surface grain size distributions for initial and equilibrium conditions in all runs. Plotted is the percent in each fraction against grain size. Solid diamonds are initial conditions. Open symbols are equilibrium conditions. Magnetic paint samples used for both initial and equilibrium conditions for runs 1-5. Clay samples used for runs 6 and 7 . Only one sample was taken from the equilibrium bed surface in runs 6 and 7 ; the means of multiple samples were used for all initial conditions and the equilibrium conditions in runs $1-5$.

layer contributing to the transport. Even though some grains of all size fractions are found in transport in all of our runs, some of the individual coarse grains will, as the run progresses, find stable resting places and become essentially immobile, forming a partial static armor. A similar partial armoring was described by Proffitt and Sutherland [1980; 1983]. although in their case the partial armor was observed during the process of complete armor development (no sediment input), whereas the partial armor suggested here is present on an equilibrium transport surface. The proportion of immobile grains in any fraction presumably increases as $\tau$ approaches $\tau_{1}$. Although we made no explicit test of the number of immobile coarse grains, we did note on occasion that particular grains in the coarse surface layer did not 


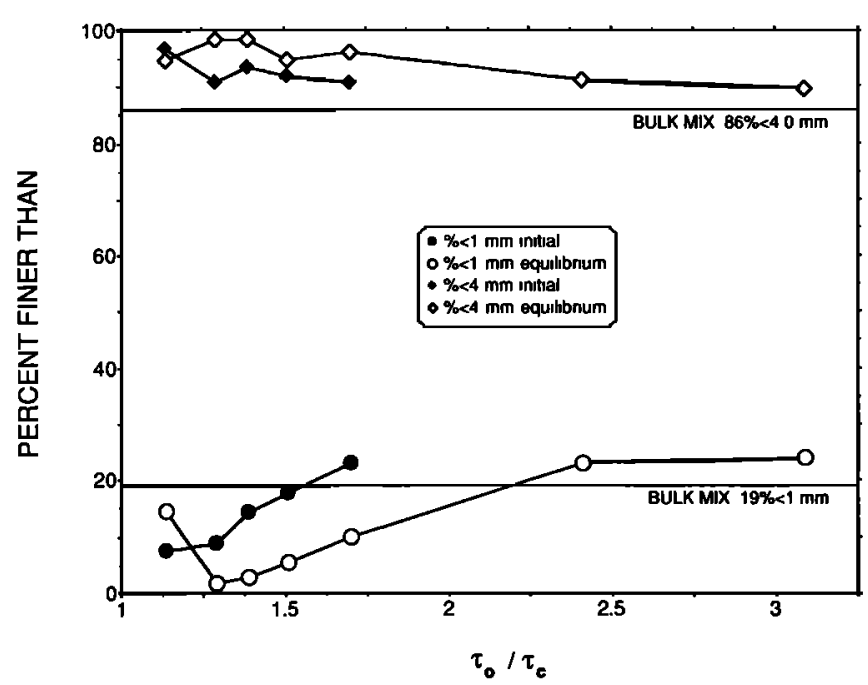

Fig. 11. Variation of initial and equilibrium transport grain size distributions with $\tau / \tau_{c}$. Plot symbols represent the percent finer than 4 and $1 \mathrm{~mm}$ in transport. Corresponding values for volumetric samples of the bulk sediment mix are given as horizontal lines.

move over periods of hours or did not move as successive bed form troughs moved past them. As a run progressed, the number of coarse grains in the static armor should have increased, as individual grains found stable resting places on the bed surface, so the proportion of coarse grains in transport can decrease with time. These time-dependent relations should become less apparent at stronger flows if fewer coarse grains become immobile as $\tau$ increases. Bed forms were present in runs 3,4 , and 5 and increased in size with $\tau$. The bed forms exposed a larger number of coarse grains to active transport. Size-dependent vertical sorting can then serve to concentrate these coarser grains on the bed surface over which the bed forms move. The bed forms act to "mine" the bed for coarser grains, a disproportionate number of which are left on the bed surface. Runs 1 and 2, which had a plane bed at equilibrium, showed only negligible coarsening of the bed surface. The next three runs, which had long, low dunes, showed a distinct coarsening of the bed surface. Although a partial static armor explains the decrease with time of coarse fractions in transport, any decrease in this trend as $\tau$ increases can be explained by both bed form "mining", increasing the proportion of coarse grains on the bed surface, and increased $\tau$, reducing the proportion of immobile grains on the bed surface.

It is worth noting that this interpretation of the mutual adjustment between the bed surface and the transport would not be possible within the paradigm that the proportion of each fraction present on the bed surface reflects an adjustment that produces equal mobility for each fraction. This problem is well illustrated by the fact that we observe the coarse surface layer to become better developed with $\tau$, a trend that contrasts with the mobile armoring model offered by Parker and Klingeman [1982] and Andrews and Parker [1987]. This model is based on the premise that inherent size-dependent differences in mobility are greatest at $\tau$, and decrease with increasing $\tau$, a trend we also observe, most clearly in our start-up samples. If equilibrium transport requires equal mobility, the bed surface texture must compensate for these differences, and the coarse surface layer should be best developed near $\tau_{c}$ and decrease in strength as $\tau$ increases. We do not observe this trend in our data because a recirculating system need not achieve equal mobility to achieve equilibrium transport. In our runs the processes leading to a coarse surface layer, which include the development of a partial static armor, vertical bed sorting, and bed form mining of coarse grains, produce a stronger coarse surface layer as $\tau$ increases, at least to the point where the coarse surface layer is entirely broken up by the intense flow in the lee of bed forms.

Runs 6 and 7. No coarse surface layer was evident at the conclusion of these runs, and no overrepresentation of coarser fractions was found in the bed form troughs (Figures 7 and 10). The coarse-fraction transport rates approached, but did not reach, equal mobility in these strongest runs (Figures 9 and 11). Because no coarse surface layer was present, these runs form an approximate continuation of the well-mixed initial condition portions of runs $1-5$. The startup transport size distributions of runs $1-5$ and the equilibrium transport size distributions of runs 6 and 7 show a steady increase in the mobility of the coarsest fractions.

\section{Finer Fractions}

Runs 1-5. The fractional transport rates of the finer fractions decreased with time for each of these five runs (Figure 9). With the exception of run 1, the proportion of fine fractions in transport also decreased from initial to equilibrium conditions (Figure 11). The proportion of fine fractions in run 1 was able to increase while its fractional transport rate decreased because the total transport rate decreased dramatically with time, indicating the development of a partial static armor. The proportion of fine fractions on the bed surface decreased with time in runs 1 and 2 and remained relatively constant in runs 3,4 , and 5 . For runs 1 and 2 , both of which have planar equilibrium bed surfaces, the proportion of fine grains in transport and on the bed both decreased with time. For runs 3, 4, and 5 the proportion of fine grains in transport also decreased with time, even though the proportion of fine grains on the bed surface did not change with time. This suggests that some proportion of the finer grains form part of the partial static armor and are hidden from the flow by larger neighboring immobile grains. The fine grains are concentrated within and below the coarse trough surface, having been preferentially extracted from the transporting sediment which is moving as bed forms over the bed (trough) surface. It is worth noting that in runs 3, 4, and 5 the fine fractions were not preferentially removed from the bed surface and deposited in a fine sublayer. Rather, their decreased mobility appears to be due to decreased flow exposure and increased relative bed roughness related to the coarse partial static armor.

Runs 6 and 7. The proportion of finer grains on the bed surface was essentially unchanged from the well-mixed start-up bed conditions to the equilibrium conditions (Figures 7 and 10). The equilibrium transport of the finer fractions was close to, or slightly greater than, equal mobility. Although we did not sample the transport at the beginning of these runs, it is likely that the proportion of fine fractions in transport was near equal mobility, because the fine fractions were near equal mobility for the well-mixed start-up bed conditions of runs 4 and 5 , as well as for the well-mixed equilibrium bed conditions in runs 6 and 7. Thus it seems likely that the fractional transport rates of the finer fractions, like their proportion of the bed surface, changed 
little from start-up to equilibrium conditions. In these strongest runs, differences in mobility (whether inherent or related to vertical sorting) disappeared as the bed surface became more homogeneous.

\section{The Role of Bed Forms in the Adjustment of Fractional Transport Rates and the CoARse SURFACE LAYER}

Bed forms may both influence and be influenced by the development of a coarse surface layer. In runs 3, 4, and 5, well-developed dunes coexisted with a distinct coarse surface layer. The coarse surface layer, by providing a relatively immobile surface below which bed form troughs may not scour, may serve to limit the height of the bed forms, the depth of the bed form troughs, and the variability in bed form size. At these flow strengths the bed forms may actually play a role in limiting their size range by increasing the number of coarse grains exposed to active transport, thereby providing more grains with which to armor the bed surface. Prior to these runs, it was not clear whether bed forms and coarse surface layers were mutually exclusive, with a coarse surface layer inhibiting the development of bed forms or the intense flow in the lee of bed forms preventing development of any coarse surface layer. At the highest flow rates we measured (runs 5 and 6), flow in the lee of the bed forms did become sufficiently strong to break up the coarse surface layer. Even without the presence of bed forms, it is possible that the coarse surface layer would vanish at higher flows because the size-dependent differences in grain mobility and the strength of a partial static armor would both decrease with $\tau$. The presence of intense flow in the lee of the bed forms may cause the coarse surface layer to break up at a lower $\tau$ than would occur without bed forms. It is difficult to test the bed form effect in any definitive manner because bed forms are an inherent and inextractable part of the transport problem for those sediments in which bed forms naturally occur. Any means of suppressing bed form growth would involve important changes to the entire transport system that would prevent direct comparisons.

\section{List OF CONCLUSIONS}

1. We measured fractional transport rates above a wellmixed sediment bed that was identical from run to run. We found that the fine and coarse fractions are somewhat less mobile $\left(p_{t} / f,<1\right)$ than the central fractions and that this size-dependent difference in mobility decreases as the bed shear stress increases. The fine fractions reach a condition of equal mobility $\left(p_{l} / f_{l}=1\right)$ at $\tau>1.5 \tau_{i}$; the coarse fractions approach, but do not reach, equal mobility for the range of flows for which we collected transport samples from the well-mixed start-up bed $\left(\tau<1.75 \tau_{\varepsilon}\right)$. Because the bed surface was identical from run to run, we can clearly demonstrate that the mobility of individual size fractions depends on both grain size and flow strength.

2. At values of $\tau<2 \tau_{c}$, when the bed and transport adjust from the well-mixed start-up condition toward an equilibrium condition, the mobility of the fine and coarse fractions consistently decreases with time, moving away from a condition of equal mobility. This process cannot be explained with a conceptual model that states that all size fractions must adjust toward equal mobility for equilibrium transport. An equilibrium transport system must operate at equal mobility only in the special case of a perfect feed system in which the material of the sediment bed is used as the feed material. Feed and recirculating flumes can produce very different equilibrium transport conditions, even when the same initial flow and sediment bed are used. In nonfeed systems, equilibrium transport may occur at conditions far from equal mobility, as demonstrated in our experiments.

3. The decrease in mobility of the fine and coarse fractions as the system adjusts toward equilibrium is explained by the development of a partial static armor, wherein some proportion of grains from the coarse fractions find stable resting places and become effectively immobile, even though grains from all fractions are still found in transport. The development of a partial static armor also appears to decrease the mobility of the fine fractions, which are underrepresented in the transport even though they are not underrepresented on the bed surface.

4. The degree to which the equilibrium transport departs from equal mobility decreases as the bed shear stress increases. This trend is attributed to a decrease in the sizedependent variation in grain mobility at higher $\tau$ (demonstrated by a similar variation in our start-up runs), the disappearance of a partial static armor as the proportion of immobile grains decreases, and the scour of any sorted bed surface by moving bed form troughs.

5. We have clearly demonstrated that a coarse surface layer can develop as a mixed size sediment bed adjusts toward equilibrium transport. This coarse surface layer need not serve as a regulator of the mobility of different size fractions except in the special case of a sediment feed flume. Its presence in our recirculating flume data is a result of size-dependent variation in grain mobility, development of a partial static armor, and a geometrically necessary vertical sorting process that occurs when at least some of all sizes are in motion. Bed forms also contribute to the development of a coarse surface layer by increasing the supply of coarse grains available for transport. We observed the coarse surface layer to become better developed as $\tau$ increases, up to the point where intense flow in the lee of bed forms breaks up any surface grain size sorting. This trend in the development of a coarse surface layer is not possible in a feed system, which must operate at equal mobility to achieve equilibrium transport conditions.

6. The degree to which natural mixed size transport systems may be represented by feed or recirculating flumes depends on the time and space scales of the problem. Cases with very long time or space scales will tend to be feed systems, but equilibrium transport is rare in these cases. Cases with very short time or space scales have a larger recirculating component. In cases where the sediment transport, bed surface texture, and bed configuration achieve a short-term equilibrium (on time scales of hours), the equilibrium conditions are determined primarily by the sediment bed and flow conditions. This is a typical prediction problem for sediment transport and is best modeled by a recirculating flume. Uncertainty in the choice between feed and recirculating models of mixed size sediment transport is partially resolved by the observation that unimodal and weakly bimodal sediment mixtures appear to operate at close to equal mobility in both feed flumes and recirculating flumes for $\tau>2 \tau_{c}$.

7. A coarse surface layer and bed forms coexist over a finite range of $\tau$. When both are present, the coarse surface 
layer does not constitute the entire bed surface that is visible at any time, but is exposed only in bed form troughs. The coarse surface layer is the surface on which, or through which, size-dependent exchange of grains occurs. As such, the coarse surface layer plays a role in determining the grain size distribution of the transported sediment and therefore of the bed forms. In the range of $\tau$ where both bed forms and a coarse surface layer exist the coarse surface layer may serve to regulate the size and variability of the bed forms by limiting the depth of scour in the bed form troughs. Above this range, bed scour in the lee of the bed forms is sufficiently strong to prevent the development of a vertically sorted bed surface. Bed forms may limit the range of $\tau$ over which a coarse surface layer may develop; the type and size of bed forms may also be controlled by the occurrence of a coarse surface layer.

\section{REFERENCES}

Andrews, E. D., and G. Parker, Formation of a coarse surface layer as the response to gravel mobility, in Sediment Transport in Gravel-bed Rivers, edited by C. R. Thorne, J. C. Bathurst, and R. D. Hey, John Wiley and Sons, New York, 1987.

Church, M. A., D. G. McLean, and J. F. Wolcott, River bed gravels: Sampling and analysis, in Sediment Transport in Gravelbed Rivers, edited by C. R. Thorne, J. C. Bathurst, and R. D. Hey, John Wiley and Sons, New York, 1987.

Day, T. J., and P. Egginton, Particle-size distributions for the surface of alluvial channel beds, Curr. Res., Part B, Pap. 83-IB, pp. 299-302, Geol. Surv. of Can., Ottawa, 1983.

Dhamotharan, S., A. Wood, G. Parker, and H. Stefan, Bedload transport in a model gravel stream, Proj. Rep. 190, St. Anthony Falls Hydraul. Lab., Univ. Minn., Minneapolis, 1980.

Diplas, P., and A. J. Sutherland, Sampling techniques for gravel sized sediments. J. Hydraul. Eng., I14(5), 484-501, 1988.

Iseya, F., and H. Ikeda, Pulsations in bedload transport rates induced by a longitudinal sediment sorting: A flume study using sand and gravel mixtures, Geogr. Ann., 69(A), 15-27, 1987.

Kellerhals, R., and D. I. Bray, Sampling procedures for coarse alluvial sediments, J. Hydraul. Div. Am. Soc. Civ. Eng., 97(HY8), $1165-1180,1971$.

Klaassen, G. J., J. S. Ribberink, and J. C. C. de Ruiter, On the transport of mixtures in the dune phase, paper presented at Euromech 215, European Mechanics Committee, Genova, Italy Sept. 15-19, 1987.

Kuhnle, R. A., and J. B. Southard, Bed load transport fluctuation in a gravel bed laboratory channel, Water Resour. Res., 24(2), 247-260, 1988.
Milhous, R. T., Sediment transport in a gravel-bottomed stream, Ph.D. thesis, Oregon State Univ., Corvallis, 1973.

Parker, G., Experiments on the formation of mobile pavement and static armor, technical report, Dept. Civ. Eng., Univ. Alberta, Edmonton, 1980.

Parker, G., and P. C. Klingeman, On why gravel bed streams are paved, Water Resour. Res., 18, 1409-1423, 1982.

Parker, G., S. Dhamotharan, and S. Stefan, Model experiments on mobile, paved gravel bed streams, Water Resour. Res., 18(5), 1395-1408, 1982a.

Parker, G., P. C. Klingeman, and D. L. McLean, Bedload and size distribution in paved gravel-bed streams, J. Hydraul. Div. Am. Soc. Civ. Eng., 108(HY4), 544-571, $1982 b$.

Proffitt, G. T., and A. J. Sutherland, Self armouring on non-uniform alluvial sediments, paper presented at 7 th Australasian Hydraulics and Fluid Mechanics Conference, Institute of Engineers, Australia Brisbane, Australia, Aug. 1980.

Proffit, G. T., and A. J. Sutherland, Transport of non-uniform sediments, J. Hydraul. Res., 2l(1), 33-43, 1983.

Sutherland, A. J., Static armor layers by selective erosion. in Sediment Transport in Gravel-bed Rivers, edited by C. R. Thorne, J. C. Bathurst, and R. D. Hey, John Wiley and Sons, New York, 1987.

Wilcock, P. R., Bed-load transport of mixed-size sediment. Ph.D. thesis, Mass. Inst. of Technol., Cambridge, Mass., 1987.

Wilcock, P. R., Methods for estimating the critical shear stress of individual fractions in mixed-size sediment, Water Resour. Res., 24(7), 1127-1135, 1988.

Wilcock, P. R., and J. B. Southard, Bed configuration, bed surface texture, and fractional transport rates (abstract), Eos Trans. $A G U, 68,1292,1987$.

Wilcock, P. R., and J. B. Southard, Experimental study of incipient motion in mixed-size sediment, Water Resour. Res., 24(7), 1137$1151,1988$.

Wilcock, P. R., and R. S. Stull, Magnetic paint sampling of the surface and subsurface of clastic sediment beds, $J$. Sediment. Petrol, in press, 1989.

J. B. Southard, Department of Earth, Atmospheric, and Planetary Sciences, Massachusetts Institute of Technology, Cambridge, MA 02139.

P. R. Wilcock, Department of Geography and Environmental Engineering, The Johns Hopkins University, Baltimore, MD 21218.

(Received December 29, 1988; revised March 31, 1989; accepted April 11, 1989.) 